\title{
Dynamics of Bacterial Hand Contamination During Routine Neonatal Care
}

\author{
$\square$ \\ Carmem Lúcia Pessoa-Silva, MD; Sasi Dharan, MT; Stéphane Hugonnet, MD, MSc; Sylvie Touveneau, RN; Klara Posfay-Barbe, MD; \\ Riccardo Pfister, MD; Didier Pittet, MD, MS
}

\begin{abstract}
OBJECTIVE: To evaluate the dynamics of bacterial contamination of healthcare workers' (HCWs) hands during neonatal care.

SETTING: The 20-bed neonatal unit of a large acute care teaching hospital in Geneva, Switzerland.

METHODS: Structured observation sessions were conducted. A sequence of care began when the HCW performed hand hygiene and ended when the activity changed or hand hygiene was performed again. Alcohol-based handrub was the standard procedure for hand hygiene. An imprint of the five fingertips of the dominant hand was obtained before and after hand hygiene and at the end of a sequence of care. Regression methods were used to model the final bacterial count according to the type and duration of care and the use of gloves.
\end{abstract}

RESULTS: One hundred forty-nine sequences of care

Hand hygiene remains the single most important measure to prevent cross-transmission of microorganisms ${ }^{1}$ and reduces patient morbidity and mortality from nosocomial infections, ${ }^{2,3}$ a major complication of hospital care in the pediatric population. ${ }^{4-9}$ Nosocomial infections affect up to $30 \%$ of neonates, ${ }^{5,10-13}$ and rates can be more than five times higher in this population compared with older children.10,11 Of major concern is the high proportion (approximately $40 \%$ ) of bloodstream infections, ${ }^{14}$ which are associated with increased mortality, prolonged hospital stay, and slower growth among infants with very low birth weights. ${ }^{15-17}$

Compliance with hand hygiene recommendations ${ }^{1,18}$ may be difficult to achieve when caring for neonates, particularly those who are hospitalized in intensive care units. ${ }^{19}$ Similar to other settings, observed compliance with hand hygiene has been reported as no better than $40 \%$. Few studies, however, support current guidelines on indications for hand hygiene. ${ }^{20}$ Earlier guidelines present vague recommendations on indications for hand hygiene and put the responsibility on the healthcare worker ( $\mathrm{HCW}$ ) to assess the risk of potential hand contamination and decide for or against hand were observed. Commensal skin flora comprised $72.4 \%$ of all culture-positive specimens $(n=360)$. Other microorganisms identified were Enterobacteriaceae $(\mathrm{n}=55,13.8 \%)$; Staphylococcus aureus $(\mathrm{n}=10,2.5 \%)$; and fungi $(\mathrm{n}=7,1.8 \%)$. Skin contact, respiratory care, and diaper change were independently associated with an increased bacterial count; the use of gloves did not fully protect $\mathrm{HCW}$ ' hands from bacterial contamination.

CONCLUSIONS: These data confirm that hands become progressively contaminated with commensal flora and potential pathogens during neonatal care, and identify activities at higher risk for hand contamination. They also reinforce the need for hand hygiene after a sequence of care, before starting a different task, and after glove removal (Infect Control Hosp Epidemiol 2004;25:192-197).

hygiene ${ }^{20}$ Some studies suggest a ranking of patient care activities $^{21,22}$ that are likely to cause hand contamination as a tool to define hand hygiene indications, although such systems lack scientific validation. ${ }^{18}$ In particular, opportunities for adequate hand hygiene in the neonatal setting have not yet been defined.

We studied the dynamics of bacterial contamination of HCWs' hands during routine neonatal care to help identify high-risk opportunities for hand contamination.

\section{METHODS \\ Setting}

The study was conducted from March 26 to April 9, 2001 , in the neonatal unit of the University of Geneva Hospitals, a large referral institution providing primary and tertiary medical care for residents of Geneva, Switzerland, and the surrounding area (population of approximately 800,000 ).

The neonatal unit is divided into two sections located in separate areas: intermediate care consists of 3 patient care pods (12 beds) and intensive care consists of 2 pods ( 8 beds). Approximately 700 neonates (5,200 patient-days) are

Dr. Pessoa-Silva, Mr. Dharan, Dr. Hugonnet, Ms. Touveneau, and Dr. Pittet are from the Infection Control Program, Department of Internal Medicine and Drs. Posfay-Barbe and Pfister are from the Department of Pediatrics, University of Geneva Hospitals, Geneva, Switzerland. Address reprint requests to Professor Didier Pittet, MD, MS, Director, Infection Control Program, Department of Internal Medicine, University of Geneva Hospitals, 24 Rue Micheli-du-Crest, 1211 Geneva 14, Switzerland.

Supported by a grant from the Conselho Nacional de Desenvolvimento Cientifico e Tecnológico (CNPq), Nr 200694/99-5.

The authors thank Nhi Nguyen Thai Hiep for laboratory and data management support and Rosemary Sudan for editorial assistance. 
admitted annually to the unit. Handwashing facilities are conveniently located throughout, with one manual sink, medicated soap (chlorhexidine gluconate 4\%), and paper towels inside every pod, and alcohol-based handrub solution is widely available. ${ }^{23}$ The average patient-to-nurse ratio is $3: 2$ and $1: 1$ in the intermediate and intensive care sections, respectively. Clinical staff includes 17 physicians and 84 registered nurses.

\section{Definitions}

Rubbing hands with an alcohol-based $(75 \% \mathrm{vol} / \mathrm{vol}$, isopropanol) preparation of chlorhexidine gluconate (0.5\%) (Hopirub, B. Braun Medical AG, Sempach, Switzerland) was defined as the standard procedure for hand hygiene before and after patient care activities, unless hands were visibly soiled. ${ }^{18}$ In this case, $\mathrm{HCW}$ s performed handwashing with medicated soap ( $4 \%$ chlorhexidine gluconate). Common neonatal patient care activities selected for study were defined according to types of contact ${ }^{22}$ and included skin contact; respiratory tract care; contact with secretions other than respiratory (ocular, oral, or gastric tubes); change of diapers; manipulation of vascular access devices (blood sampling or intravenous set connections); and contact with equipment related to the neonate (incubator, monitor, or ventilator). An observation period started when the observer initiated the structured observation and could include more than one sequence of care. A sequence of care started when the $\mathrm{HCW}$ performed hand antisepsis using an alcohol-based handrub and ended when he or she changed activity or reapplied handrub.

\section{Study Procedures}

Bacterial contamination of $\mathrm{HCWs}$ ' hands was assessed as previously described. ${ }^{24}$ Briefly, two trained external observers conducted structured observation sessions during routine neonatal care. During each session, the HCW's activity was interrupted at three points to obtain bacterial samples from the hands: before and after applying handrub and at the end of a sequence of care, but before applying new handrub. When nonsterile disposable latex gloves were used during the activity, an imprint of the fingertips was obtained before gloving, after gloving, and at the end of care immediately before and after glove removal. Reliability of data collection has been established in a previous study. ${ }^{24}$ Collected variables included the day of life of the neonate receiving care; the type and duration of care; and the use of gloves. Observation sessions were randomly distributed according to the unit workload and covered all shifts. Informed consent was obtained from each $\mathrm{HCW}$ before initiation of the observation, and personnel were requested to perform patient care activities as usual. The study was approved by the institutional review board.

\section{Microbiologic Procedures}

Imprints of the five fingertips of the HCW's dominant hand were obtained using commercial contact plates (COUNT-TACT, bioMérieux SA, Marcy l'Etoile, France).
Fingertips were pressed for 5 seconds onto a plate. Plates were transferred to the laboratory, where they were incubated at $35^{\circ} \mathrm{C}$ under aerobic conditions. An initial colony count was performed at 24 hours and a final count at 48 hours of incubation as previously described. ${ }^{24}$ The maximal colony count was fixed at 300 colony-forming units (CFU); beyond this, growth is confluent and counting is inaccurate. Bacteria were identified by Gram stain, growth on MacConkey agar, API 20 E (bioMérieux SA) profiling, and the slide agglutination test with Pastorex Staph Plus (Bio-Rad, Mannes la Coquette, France) for Staphylococcus aureus.

\section{Statistical Analysis}

The main outcome measure was the number of $\mathrm{CFU}$ on the ungloved fingertips of the HCW's dominant hand at the end of the sequence of care. Residual bacteria counts after handrub and on gloved fingertips were also assessed as secondary outcomes. A nonparametric regression model (locally weighted regression [LOWESS]) was used to explore the trend in CFU counts according to the duration of each type of care. ${ }^{24}$ Linear regression was used to model the final bacterial count according to predictors (the type and duration of care and the use of gloves). Explanatory variables with a level of significance of 0.25 or less were entered in a multivariate model. The Wilcoxon signed rank test for paired observation was used for comparison of bacteria counts before and after applications of handrub. All tests were two-tailed, and the selected threshold level for statistical significance was a $P$ value of less than .05. Analyses were conducted using STATA software (version 7; STATA Corp., College Station, TX).

\section{RESULTS}

One hundred five structured observation periods, representing a total of 11 hours and 14 minutes, were conducted (median duration, 5.0 minutes; range, 1.5 to 25 minutes) and analyzed during the study. These included 149 sequences of care, 14 with and 135 without the use of gloves (median duration, 3.0 minutes; range, 0.5 to 14 minutes). Observations involved $31 \%(n=31)$ of the HCWs in the neonatal unit. The median age of the neonates being cared for was 13 days (range, 1 to 31 days).

\section{Bacterial Contamination}

Of 398 samples from ungloved hands, 360 (90.5\%) were culture positive. Skin flora microorganisms (coagulase-negative staphylococci, Corynebacterium species, and Micrococcus species) were isolated in $72.4 \%$ of all positive cultures. Other microorganisms included Enterobacteriaceae $(\mathrm{n}=55,13.8 \%), S$. aureus $(\mathrm{n}=10$, $2.5 \%)$, and filamentous fungi $(\mathrm{n}=7,1.8 \%)$. Most Enterobacteriaceae-positive samples (39 of 55) were obtained following the care of neonates older than 14 days. Patient care activities included diaper change (15 of 55), contact with equipment ( 13 of 55), and respiratory care (11 of 55). Coagulase-negative staphylococci were equally distrib- 
TABLE 1

Bacterial Contamination of Ungloved Healthcare Workers' Hands During I35 Sequences of Care Among Neonates in the Neonatal Unit at the University of Geneva Hospitals, Geneva, Switzerland, March to April 2001

\begin{tabular}{|c|c|c|c|c|c|c|}
\hline Type of Sequence of Care & No. $(\%)$ & $\begin{array}{c}\text { Medlan } \\
\text { Duration (min) } \\
\end{array}$ & $\begin{array}{c}\text { Range of } \\
\text { Duration (m/n) }\end{array}$ & $\begin{array}{c}\text { Increase in } \\
\text { Bacterlal Count } \\
\text { (CFU/mln) }\end{array}$ & $\mathrm{Cl}_{95}$ & $\boldsymbol{P}$ \\
\hline Skin contact & $27(20.0)$ & 3.0 & 1.5 to 11.0 & 21.2 & 5.8 to 36.5 & .008 \\
\hline Diaper change & $17(12.6)$ & 4.0 & 2.0 to 9.5 & 41.9 & 28.7 to 55.1 & $<.001$ \\
\hline Respiratory tract care & $22(16.3)$ & 4.0 & 1.5 to 14.5 & 37.6 & 20.4 to 54.82 & $<.001$ \\
\hline $\begin{array}{l}\text { Contact with body secretions other than } \\
\text { respiratory }\end{array}$ & $23(17.0)$ & 2.5 & 1.0 to 10.0 & 20.1 & 9.9 to 30.4 & $<.001$ \\
\hline Manipulation of vascular access devices & $22(16.3)$ & 5.0 & 1.5 to 12.5 & 10.0 & 2.1 to 18.0 & .015 \\
\hline Contact with equipment & $24(17.8)$ & 1.5 & 0.5 to 11.5 & 9.1 & 3.1 to 15.2 & $<.004$ \\
\hline Total & $135(100.0)$ & 3.0 & 0.5 to 14.0 & 20.4 & 15.3 to 25.6 & $<.001$ \\
\hline
\end{tabular}

$\mathrm{CFU}$ - colony-forming units; $\mathrm{Cl}_{95}=95 \%$ confidence interval.

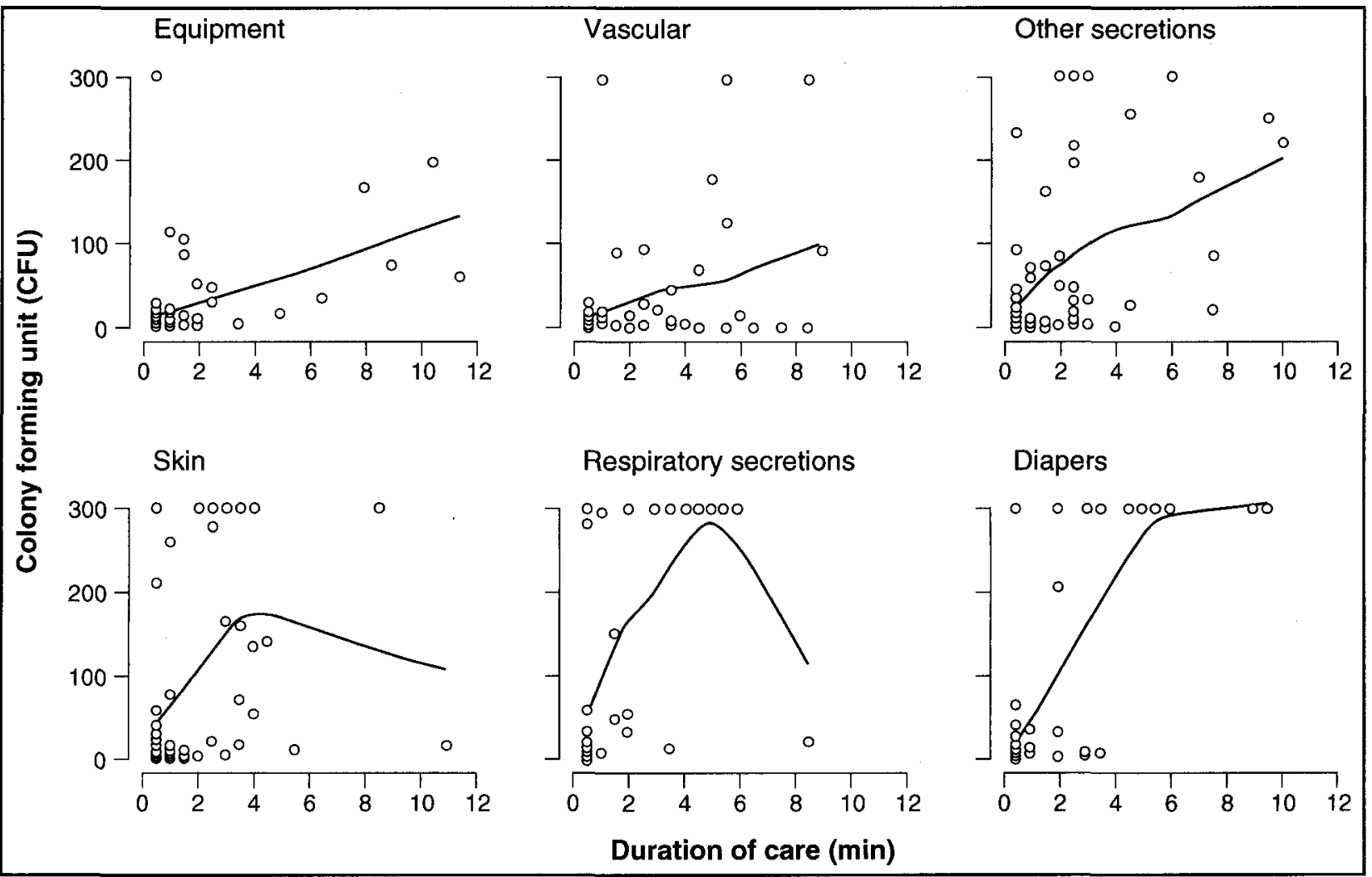

FIGURE. Dynamics of bacterial contamination of ungloved healthcare workers' hands in 135 observations according to different patient care activities in the neonatal unit at the University of Geneva Hospitals, Geneva, Switzerland, from March to April 2001.

uted according to type of contact or neonatal age. All samples from fingertips after glove removal $(n=31)$ were culture positive with skin flora comprising $84 \%$, Enterobacteriaceae comprising $12.9 \%$, and $S$. aureus comprising $3.3 \%$.

\section{Predictors of Bacterial Contamination of HCW' Hands}

On average, a significant increase in bacterial counts (CFU/min) on ungloved HCWs' hands was observed in all types of care (Table 1). The dynamics of hand contamination showed that after 2 minutes of certain types of contact (skin and diaper change), bacterial counts can be as high as $100 \mathrm{CFU}$, or even higher during respiratory care (Figure). Neonatal age was not associated with HCW hand contamination $(P=.736)$.

During the 14 sequences with the use of gloves (respiratory care, $n=6$; diaper change, $n=5$; and vascular access manipulation, $\mathrm{n}=3$ ), a reduced final bacterial count was 
TABLE 2

Multiple Linear Regression MODEl for Predictors of Bacterial Contamination of Healthcare Workers' Hands IN 149 OBSERVATIONS IN THE NEONATAL UNIT AT THE UNIVERSTTY of Geneva Hospitals, Geneva, Switzerland, March to April 2001

\begin{tabular}{llc}
\hline Predlctor & \multicolumn{1}{c}{$\begin{array}{c}\text { CFU Count } \\
\left.\text { (C) }_{95}\right)\end{array}$} & $\boldsymbol{P}$ \\
\hline $\begin{array}{l}\text { Contact with equipment } \\
\text { Manipulation of vascular }\end{array}$ & $3.6(-28.0$ to 35.2$)$ & .820 \\
$\quad-2.9(-43.7$ to 37.9$)$ & .890 \\
access devices & $32.7(-8.3$ to 73.6$)$ & .120 \\
$\quad$ Contact with secretions & & \\
other than respiratory & $58.8(18.6$ to 98.9$)$ & .004 \\
Diaper change & $81.8(39.6$ to 124.0$)$ & $<.001$ \\
Respiratory care & $98.9(57.7$ to 140.1$)$ & $<.001$ \\
Use of gloves & $-64.5(-107.0$ to -22.1$)$ & .003 \\
Duration of care, min & $15.3(10.9$ to 19.7$)$ & $<.001$ \\
\hline
\end{tabular}

$\mathrm{CF} \mathrm{U}$ = colony-forming units; $\mathrm{CI}_{95}-95 \%$ confidence interval.

observed on the ungloved fingertips as compared with sequences involving the same types of contact during which gloves were not used. HCWs who did not wear gloves acquired, on average, $24.5 \mathrm{CFU} / \mathrm{min}$ ( $95 \%$ confidence interval $\left[\mathrm{CI}_{05}\right], 16.2$ to $32.8 \mathrm{CFU} / \mathrm{min} ; P<.001$ ) as compared with $-1.9 \mathrm{CFU} / \mathrm{min}\left(\mathrm{CI}_{95},-11.5\right.$ to $\left.7.7 \mathrm{CFU} / \mathrm{min} ; P=.690\right)$ among those who did. However, glove contamination was clearly demonstrated during respiratory care $\left(16.7 \mathrm{CFU} / \mathrm{min}\right.$; $\mathrm{CI}_{95}$, 0.6 to $32.8 \mathrm{CFU} / \mathrm{min} ; P=.043)$ and diaper change $(78.3$ $\mathrm{CFU} / \mathrm{min} ; \mathrm{CI}_{95}, 47.5$ to $\left.109.1 \mathrm{CFU} / \mathrm{min} ; P<.001\right)$.

\section{Multivariate Model}

The type and duration of care and the use of gloves significantly predicted bacterial hand contamination (Table 2). Whereas the use of gloves protected the hands of HCWs from bacterial contamination, skin contact, diaper change, and respiratory care were associated with a significant increase in bacterial contamination. In a predictive model using the median duration of the sequence of care ( 3 minutes), all types of contact were associated with a significant increase in bacterial counts, with the exception of the manipulation of vascular access devices with the use of gloves (Table 3). Although the average bacterial counts were lower when gloves were used, a significant increase in CFU counts was still observed on hands following glove removal during diaper change and respiratory care.

\section{Effect of Handrub}

We measured bacterial counts on fingertips before and after the application of handrub in 93 episodes of hand antisepsis. Bacterial contamination was significantly reduced following handrub; median CFU counts before and after hand antisepsis were 61 (range, 0 to 300 ; interquartile range, 10 and 281) and 4 (range, 0 to 209; interquartile range, 1 and $14 ; P<.001$ ), respectively. This
TABLE 3

Predictive Model for Bacterial Contamination of Healthcare Workers' Hands After 3 Minutes of Patient Care IN THE Neonatal UNIT at THE University of GeneVA Hospitals, Geneva, SwTtzerland, March to April 2001*

\begin{tabular}{lcc}
\hline $\begin{array}{l}\text { Type of } \\
\text { Contact }\end{array}$ & $\begin{array}{c}\text { Average Increase } \\
\text { in CFU }\end{array}$ & \multicolumn{1}{c}{$\mathbf{C i}_{\mathbf{9 5}}$} \\
\hline $\begin{array}{l}\text { Contact with equipment } \\
\text { Manipulation of vascular }\end{array}$ & 49.54 & 18.65 to 80.43 \\
$\begin{array}{l}\text { access devices } \\
\text { With gloves }\end{array}$ & & \\
$\quad$ Without gloves & -17.87 & -64.50 to 28.74 \\
Contact with secretions & 46.67 & 19.40 to 73.94 \\
$\quad$ other than respiratory & 82.22 & 54.42 to 110.02 \\
Skin contact & 108.31 & 81.50 to 135.12 \\
$\begin{array}{l}\text { Diaper change } \\
\text { With gloves }\end{array}$ & & \\
$\quad \begin{array}{l}\text { Without gloves } \\
\text { Respiratory care }\end{array}$ & 66.83 & 23.25 to 110.41 \\
With gloves & 131.36 & 72.48 to 190.25 \\
Without gloves & & \\
\end{tabular}

$\mathrm{CFU}=$ colony-forming units; $\mathrm{CI}_{95}=95 \%$ confidence interval.

*Multiple linear regression.

reduction was independent of the type of bacterial contamination: skin flora microorganisms $(P=.003)$; Enterobacteriaceae $(P=.004)$; and $S$. aureus $(P=.030)$.

\section{DISCUSSION}

Our study showed that all types of care that did not include the use of gloves were associated with a significant increase in the bacterial contamination of HCWs' hands. Therefore, it seems that the term "clean" care, as it has been proposed, ${ }^{21,22}$ may no longer be appropriate. To our knowledge, this is the first study to evaluate the degree of hand contamination of HCWs during routine neonatal care. The presented data show a clear grading of the relative potential for bacterial hand contamination among different types of patient and environmental contacts in the neonatal setting, thus identifying key opportunities for hand hygiene. This information may also prove to be useful for future neonatal care planning.

Many guidelines, ${ }^{20}$ including a newly developed set, ${ }^{18}$ recommend hand hygiene between different care activities for the same patient, but few studies have evaluated this grading in terms of bacterial burden. In a previous study performed in all wards in our institution, the patient care activities that were independently associated with higher contamination levels of HCWs' hands were respiratory care, direct patient contact, and handling of body fluid secretions. ${ }^{24}$ In the current study, we selected activities from the daily neonatal scenario and individualized them in sequences of care. This approach enabled the evaluation of the dynamics of hand contamination during routine neonatal care. Although diaper change, respi- 
ratory care, and handling of secretions (other than respiratory) all refer to contact with body fluid secretions, these activities are closely linked to the routine care of neonates. Most neonatal care activities are highly integrated and involve skin contact; however, our aim was to evaluate to what extent other activities differed from pure skin contact in terms of potential for bacterial hand contamination. Despite the brief nature of neonatal care, we found that defined acts such as diaper change and respiratory care were associated with a rapid increase in bacterial counts, strongly suggesting that hand hygiene should be performed before moving to another body site for care of the same patient.

The previously reported protective effect of gloves against bacterial contamination ${ }^{24-26}$ was confirmed in the current study in the multiple regression model. Glove use protected hands better during the manipulation of vascular access devices than during diaper change or respiratory care. This could have been due to a smaller bacterial load on gloved hands with less hand contamination during glove removal. ${ }^{27,28}$ Importantly, our study showed that both commensal and pathogenic bacteria accumulate on gloves during the process of care. Possible lack of glove removal during patient care has been associated with outbreak situations. ${ }^{29}$ Although gloves protect their hands from bacterial contamination, HCWs must be aware that contaminated gloves may facilitate crosstransmission when not appropriately removed, particularly following activities associated with high bacterial load. Our findings strengthen the recent suggestions to promote hand hygiene action immediately after glove removal and to change gloves between care at different body sites for the same patient. ${ }^{18}$

Although the level of bacterial contamination on hands after contact with the close environment was lower than that after most direct patient contact, it was nonetheless significant. It has already been reported that $\mathrm{HCWs}^{\prime}$ hands may become contaminated after contact with inanimate surfaces, ${ }^{30-32}$ and the environment has been suggested as a possible reservoir for nosocomial pathogens in the hospital setting. ${ }^{32}$ None of these studies, including the current one, were designed to evaluate whether such contamination could result in pathogen transmission to susceptible patients. However, contact with a contaminated environment may play a role in high-risk newborn nurseries or neonatal intensive care units, particularly regarding bacteria that can survive for prolonged periods in inanimate environments. ${ }^{33}$

This study has several limitations. First, there is a lack of causal association between the dynamics of hand contamination and the risk of healthcare-associated infection among neonates. Further studies are needed to evaluate this link. Second, the method has limitations in that the number of bacteria expressed does not reflect total contamination, as part of the contaminating bacteria stays adhered to the skin. This has been shown under laboratory conditions by repetitive sampling of finger imprints. However, this method has been shown to be a reliable indicator of transient contamination. The alternative glove-juice method as described in the American Society for Testing and Materials Standard E1174-00 could not be adapted to our study because the study design required interruptions in the sequence that made its application unfeasible. $^{34}$

We have shown that hands become rapidly contaminated with commensal flora and, at times, with potential pathogens during routine neonatal care, reinforcing the need for hand antisepsis during the sequence of patient care or before starting a different task. The current study has also shown that bacteria accumulate on and beneath gloves during patient care and that gloving does not fully prevent hand contamination, thus emphasizing the need for hand antisepsis after glove removal. Neonates represent a particularly vulnerable population for infection, and there is a need to identify key care activities and actions for which hand hygiene is essential to prevent pathogen transmission. An awareness of this grading may help HCW s achieve compliance in a realistic manner.

\section{REFERENCES}

1. Larson EL. APIC guideline for handwashing and hand antisepsis in health care settings. Am I Infect Control 1995;23:251-269.

2. Conly JM, Hill S, Ross J, Lertzman J, Louie TJ. Handwashing practices in an intensive care unit: the effects of an educational program and its relationship to infection rates. Am J Infect Control 1989;17:330-339.

3. Doebbeling BN, Stanley GL, Sheetz CT, et al. Comparative efficacy of alternative hand-washing agents in reducing nosocomial infections in intensive care units. $N$ Engl J Med 1992;327:88-93.

4. Welliver RC, McLaughlin S. Unique epidemiology of nosocomial infection in a children's hospital. American Journal of Diseases of Children 1984;138:131-135.

5. Ford-Jones EL, Mindorff CM, Langley JM, et al. Epidemiologic study of 4,684 hospital-acquired infections in pediatric patients. Pediatr Infect Dis J 1989;8:668-675.

6. Burgner D, Dalton D, Hanlon M, Wong M, Kakakios A, Isaacs D. Repeated prevalence surveys of paediatric hospital-acquired infection. J Hosp Infect 1996;34:163-170.

7. Girard R, Fabry J, Meynet R, Lambert DC, Sepetjan M. Costs of nosocomial infection in a neonatal unit. J Hosp Infect 1983;4:361-366.

8. Leroyer A, Bedu A, Lombrail P, et al. Prolongation of hospital stay and extra costs due to hospital-acquired infection in a neonatal unit. $J$ Hosp Infect 1997;35:37-45.

9. Mahieu LM, Buitenweg N, Beutels P, De Dooy JJ. Additional hospital stay and charges due to hospital-acquired infections in a neonatal intensive care unit. J Hosp Infect 2001;47:223-229.

10. Daschner F. Analysis of bacterial infections in a neonatal intensive care unit. J Hosp Infect 1983;4:90-91.

11. Hoogkamp-Korstanje JA, Cats B, Senders RC, van Ertbruggen I. Analysis of bacterial infections in a neonatal intensive care unit. J Hos $p$ Infect 1982;3:275-284.

12. Raymond J, Aujard Y, Group ES. Nosocomial infections in pediatric patients: a European, multicenter prospective study. Infect Control Hosp Epidemiol 2000;200:260-263.

13. Sohn AH, Garrett DO, Sinkowitz-Cochran RL, et al. Prevalence of nosocomial infections in neonatal intensive care unit patients: results from the first national point-prevalence survey. J Pediatr 2001;139:821827.

14. Gaynes RP, Edwards JR, Jarvis WR, Culver DH, Tolson JS, Martone WJ. Nosocomial infections among neonates in high-risk nurseries in the United States. Pediatrics 1996;98:357-361.

15. Townsend TR, Wenzel RP. Nosocomial bloodstream infections in a newborn intensive care unit: a case-matched control study of morbidity, mortality and risk. Am I Epidemiol 1981;114:73-80.

16. Ehrenkranz RA, Younes N, Lemons JA, et al. Longitudinal growth of hospitalized very low birth weight infants. Pediatrics 1999;104:280289.

17. Pessoa-Silva CL, Myasaki CH, de Almeida F, Kopelman B, Raggio RL, Wey SB. Neonatal late-onset bloodstream infection: attributable mortality, excess of length of stay and risk factors. Eur J Epidemiol $2001 ; 17: 715-720$ 
18. Boyce JM, Pittet D. Guideline for hand hygiene in health-care settings: recommendations of the Healthcare Infection Control Practices Advisory Committee and the HICPAC/SHEA/APIC/IDSA Hand Hygiene Task Force. MMWR 2002;51(RR16):1-44.

19. Harbarth S, Pittet D, Grady L, et al. Interventional study to evaluate the impact of an alcohol-based hand gel in improving hand hygiene compliance. Pediatr Infect Dis J 2002;21:489-495.

20 . Wendt $C$. Hand hygiene: comparison of international recommendations. J Hosp Infect 2001;48(suppl):S23-S28.

21. Fox MK, Langner SB, Wells RW. How good are hand washing practices? Am J Nurs 1974;74:1676-1678.

22. Larson E, Lusk E. Evaluating handwashing technique. $J$ Adv Nurs 1985;10:547-552.

23. Pittet D, Hugonnet S, Harbarth S, et al. Effectiveness of a hospital-wide programme to improve compliance with hand hygiene. Lancet 2000;356:1307-1312.

24. Pittet D, Dharan S, Touveneau S, Sauvan V, Perneger TV. Bacterial contamination of the hands of hospital staff during routine patient care. Arch Intern Med 1999;159:821-826.

25. McFarland LV, Mulligan ME, Kwok RY, Stamm WE. Nosocomial acquisition of Clostridium difficile infection. N Engl J Med 1989; 320:204-210.

26. Tenorio AR, Badri SM, Sahgal NB, et al. Effectiveness of gloves in the prevention of hand carriage of vancomycin-resistant Enterococcus species by health care workers after patient care. Clin Infect Dis 2001;32:826-829.

27. Doebbeling BN, Pfaller MA, Houston AK, Wenzel RP. Removal of nosocomial pathogens from the contaminated glove: implications for glove reuse and handwashing. Ann Intern Med 1988;109:394-398.

28. Olsen RJ, Lynch P, Coyle MB, Cummings J, Bokete T, Stamm WE. Examination gloves as barriers to hand contamination in clinical practice. JAMA 1993;270:350-353.

29. Patterson JE, Vecchio J, Pantelick EL, et al. Association of contaminated gloves with transmission of Acinetobacter calcoaceticus var. anitratus in an intensive care unit. Am J Med 1991;91:479-483.

30. Ojajarvi J. Effectiveness of hand washing and disinfection methods in removing transient bacteria after patient nursing. $J$ Hyg (Lond) 1980;85:193-203.

31. Samore MH, Venkataraman L, DeGirolami PC, Arbeit RD, Karchmer $A W$. Clinical and molecular epidemiology of sporadic and clustered cases of nosocomial Clostridium difficile diarrhea. Am J Med 1996;100:32-40.

32. Boyce JM, Potter-Bynoe G, Chenevert C, King T. Environmental contamination due to methicillin-resistant Staphylococcus aureus: possible infection control implications. Infect Control Hosp Epidemiol 1997;18:622-627.

33. Pessoa-Silva CL, Toscano CM, Moreira BM, et al. Infection due to extended-spectrum beta-lactamase-producing Salmonella enterica subsp. enterica serotype infantis in a neonatal unit. $J$ Pediatr 2002;141:381-387.

34. American Society for Testing and Materials. Standard E1174-00: standard test method for evaluation of effectiveness of health care personnel or consumer handwash formulations. In: Annual Book of ASTM Standards. Washington, DC: American Society for Testing and Materials; 2001 